\title{
Anton Semyonovich Makarenko: um resgate para a prática educativa
}

\author{
Anton Semyonovich Makarenko: \\ a rescue for educational practice
}

\section{Anton Semyonovich Makarenko: un rescate para la práctica educativa}

\author{
SANDRA TEREZINHA URBANETZ* \\ Instituto Federal do Paraná, Curitiba- PR, Brasil.
}

\section{ELIANA NUNES MACIEL BASTOS ${ }^{* *}$}

Secretaria Municipal de Educação, Pinhais- PR, Brasil.

\section{XANA MACHADO KOSTRYCKI ${ }^{* * *}$}

Instituto Federal do Paraná, Curitiba- PR, Brasil.

\begin{abstract}
RESUMO: Este artigo tem como objetivo resgatar alguns dos ensinamentos de Anton Semyonovich Makarenko, vinculando-os à educação profissional, face aos ataques atuais à educação pública. Em sua obra Poema Pedagógico, ele relata a prática educativa diante de uma realidade complexa, de dificuldades, frente a uma mudança profunda na estrutura social vigente na época, explicita a necessidade do trabalho humanizador dos atos educativos, da organização disciplinar, mediada pelo acolhimento afetivo e da construção da autonomia, em todos os aspectos. Assim sendo, todos esses ensinamentos nos parecem extremamente atuais em função da realidade atual, principalmente da educação profissional.
\end{abstract}

* É graduada em Pedagogia pela Universidade Tuiuti do Paraná. Possui mestrado e doutorado em Educação pela Universidade Federal do Paraná. É Professora do Instituto Federal do Paraná, Campus Curitiba. E-mail: <sandra.urbanetz@ifpr.edu.br>.

* Mestranda em Educação no Instituto Federal do Paraná. Possui graduação em Pedagogia pela Faculdade de Pinhais e Pós-Graduada em Gestão Escolar. Atua como pedagoga no ensino fundamental e como professora da EJA no Rede de Ensino de Pinhais- PR. E-mail: <elianamaciel1982@gmail.com>.

*** É assistente Social no Instituto Federal do Paraná. Mestranda do Programa de Pós-Graduação em Educação Profissional e Tecnológica (ProfEPT), pela mesma instituição. E-mail:<xana.kostrycki@ifpr.edu.br>. 
Palavra-chave: Prática educativa. Makarenko. Educação profissional. Ensino.

\begin{abstract}
This article aims to rescue some of Anton Semyonovich Makarenko's teachings, linking them to professional education, in the face of current attacks on public education. In his work The Pedagogical Poem, he reports the educational practice in the face of a complex reality of difficulties, faced with a profound change in the social structure prevailing at the time, expresses the need for the humanizing work of educational acts, disciplinary organization, mediated by affective reception. and the construction of autonomy in all aspects. Therefore, all these teachings seem extremely current to us because of present-day reality, especially professional education.

Keyword: Educational practice. Makarenko. Professional education. Teaching.
\end{abstract}

Resumen: Este artículo tiene como objetivo rescatar algunas de las enseñanzas de Anton Semyonovich Makarenko, al vincularlas con la educación vocacional frente a los ataques actuales contra la educación pública. En su obra Poema pedagógico, Makarenko relata la práctica educativa frente a una realidad compleja, llena de dificultades, frente a un profundo cambio en la estructura social de la época; y explicita la necesidad del trabajo humanizador de los actos educativos, de la organización disciplinar, mediada por el acogimiento afectivo y de la construcción de la autonomía, en todos los aspectos. Por lo tanto, todas estas enseñanzas nos parecen muy pertinentes debido a la realidad actual, especialmente de la educación profesional.

Palabra clave: Práctica educativa. Makarenko. Educación profesional.

Docencia.

\title{
Introdução
}

\footnotetext{
educação contemporânea encontra-se num difuso e complexo contexto, o qual 1 é permeado de muitas contradições e desafios, situações que requerem das 1 ações educacionais uma postura cada vez mais coerente frente à preocupação de atender as reais necessidades dos educandos.
} 
Pensar nas necessidades dos estudantes é sem dúvida preocupar-se em atendê-los numa perspectiva de humanização, ou seja, disseminar uma cultura educativa crítica, humanística, nas relações que permeiam o contexto educativo, compreendendo os sujeitos em suas singularidades e trabalhando em prol de um ambiente que seja acolhedor, no sentido de que todos os indivíduos sejam sujeitos de seus processos de aprendizagem e, portanto, estejam colaborando conscientemente para que haja o sucesso na educação coletiva de todos os iguais.

Para tanto, as contribuições der Anton Semionovich Makarenko são muito importantes, trazendo a reflexão sobre a prática educativa na atualidade, tendo a premissa de exercê-la pelo viés da humanização dos atos educativos, primando pela organização disciplinar, mediada pelo acolhimento afetivo, onde o indivíduo é sublinhado na sua singularidade para contemplar a formação coletiva e eficaz de todos os partícipes do contexto educacional.

Aranha (2006), ao discorrer sobre Makarenko, afirma:

Anton Makarenko (1888-1939), importante pedagogo soviético, foi encarregado, em 1920, de dirigir a Colônia de Trabalho Gorki, instituto de reabilitação de adolescentes delinquentes, que abrigava órfãos de guerra, toxicômanos e desempregados. Entre outros escritos, defendeu suas ideias em sua obra mais famosa, Poema Pedagógico (ARANHA, 2006, p. 266).

As contribuições de Makarenko podem ser consideradas atuais, tendo em vista o trabalho educativo voltado para a formação de cidadãos, os quais em sua maioria já conviviam com as diferenças sociais pertinentes à contemporaneidade. Makarenko conviveu com imensas adversidades em seu tempo, atuou na instrução de jovens já excluídos de seus meios sociais, ajudando-os a enxergar esperança em seus caminhos por intermédio da educação. A prática educativa na educação profissional e tecnológica (EPT), da mesma forma, tem como tarefa formar cidadãos capazes de transpor os obstáculos de um mundo cada vez mais desigual e/ou desumano, propiciar uma formação integral para a atuação nos espaços sociais, políticos, econômicos e históricos, com intrepidez e criticidade. Em suma, a experiência do pedagogo soviético instiga uma prática humanística, na qual seja possível colocar-se no lugar do outro e ensinar-lhe a atuar neste mundo com a plena convicção de mudar o seu caminhar, trilhando rotas que possam lhe permitir galgar novos patamares de conquistas pessoais e profissionais, intervindo, assim, na melhoria do seu mundo e do mundo dos seus semelhantes.

Assim sendo, esse artigo propõe-se a refletir sobre a realidade da educação profissional e tecnológica a luz das provocações de Makarenko, a fim de resgatar suas contribuições para esse momento.

Aranha (2006) sublinha que:

nas condições históricas revolucionárias vividas por Makarenko, a educação exercia importante papel de politização. Ainda mais, diante do imperativo da transformação industrial do país, a formação politécnica era valorizada, mas não como estreita 
profissionalização, e sim na tentativa de unir o pensar e o agir. Ou seja, à medida que trabalhavam, os alunos teriam condições de conhecer as bases científicas das principais atividades produtivas (ARANHA, 2006, p. 267).

A correlação dos ideais pedagógicos de Makarenko com a educação profissional e tecnológica é também evidenciada quando apontam na mesma direção na concepção de educação e escola, onde a escola é tida como espaço para educar para o fim das diferenças de classes, uma educação de homens e mulheres com diferentes capacidades e diferentes necessidades, mas com direitos assegurados (FILONOV, 2010, p. 33).

\section{Os ensinamentos de Makarenko}

Um dos principais conceitos trabalhados por Makarenko diz respeito ao trabalho coletivo, dentro da perspectiva de respeito ao estudante, o que exige um planejamento de ações coletivas e cooperativas, em consonância com a defesa da ideia de autonomia de Pistrak (2009), quando este afirma que a auto-organização dos estudantes pode ser identificada na habilidade de trabalhar coletivamente, de forma organizada e no desenvolvimento da capacidade criativa. Assim, para Makarenko o grupo estimula o desenvolvimento e por isso sua proposta visava os interesses da comunidade.

É conhecido que sua ação rigorosa e sua proposta de disciplinamento buscavam formar sujeitos solidários conscientes de seu papel político, levando o estudante a ter clareza de suas responsabilidades, fato este expresso de forma clara em uma de suas frases mais famosas: "nunca mais ladrões nem mendigos: somos os dirigentes".

Outro grande ensinamento desse educador, conhecido como um educador aberto, mas rígido e duro, diz respeito à organização pedagógica, articulada ao contexto social mais amplo.

É sua a afirmação de que
a dialética da ação pedagógica é tão grande que nenhum meio pode ter efeito posi- tivo se toda uma série de outros meios não é posta em prática simultaneamente [...]. Em si, todo meio pode ser bom ou mau, sendo o elemento decisivo não sua ação isolada, mas a de um conjunto de meios harmoniosamente organizados (MAKA- RENKO, 1957, p. 258).

Isso nos faz relembrar de que nossas ações educativas, isoladamente, não fazem sentido, nem alcançam seus objetivos sociais. Para tanto, há que se retomar também a necessidade do envolvimento da família no processo, fato até hoje de difícil execução e equilíbrio. Com a publicação, em 1938, do Livro dos Pais, Makarenko pretendia demonstrar a importância da participação da família na escola e de como educar as crianças em tempos difíceis. 
Tanto em recomendações para os pais como nas normativas escolares, a disciplina aparece como um dos aspectos essenciais para o desenvolvimento pleno das potencialidades de cada estudante. Porém essa disciplina era compreendida pelo educador como um meio para que os objetivos coletivos fossem atingidos. Assim sendo, o que se buscava não era o disciplinamento imposto, mas sim o desenvolvimento da autodisciplina.

Makarenko objetivava formar os estudantes para que fossem capazes de dirigir a própria vida e também a vida do país; para tanto, a forma de organização dos trabalhos previa a divisão em pequenos grupos, de diferentes faixas etárias, que discutiam as situações escolares e escolhiam seus representantes para as reuniões mais amplas. No desenvolvimento das propostas educativas, estavam presentes aulas e atividades de música, trabalhos manuais, estudo do meio ambiente, idas ao teatro etc.

Isso aponta um desafio ainda não superado em nossa educação: nossos estudantes ainda não têm voz e nem conseguimos ainda implantar uma sistemática onde o primeiro e o último voto seja desse estudante.

\section{Mararenko e EPT}

Makarenko propõe uma postura pungente para efetivar ações em favor da constituição autônoma do sujeito educando, fazendo com que este possa ter sempre consciência de sua condição no mundo e para o mundo, suscitando uma "autogestão educativa", como sublinha Aranha (2006), ao analisar a postura pedagógica do autor soviético. Sob essa perspectiva educativa, o estudante na EPT deve ser estimulado a conhecer-se e conhecer o mundo a sua volta, para que tenha condições profissionais e pessoais de enfrentar as contradições de um mundo, predominantemente, capitalista.

Nesta leitura, o coletivo prevalece sobre o individual, a formação de um "novo homem", que compõe uma nova sociedade, solidária e igualitária perpassa todas as relações e tipos de atividades representativas da sociedade democrática. A vida da sociedade em todas as suas manifestações deve ser a base da formação do indivíduo, a dialética das inter-relações do coletivo (FILONOV, 2010, p.19).

Neste sentido, é necessário que as ações educativas estejam permeadas de diálogo, respeito e firmeza, que haja liberdade entre os partícipes educacionais, porém, que sejam conduzidos com responsabilidade e comprometimento pelos profissionais da educação, exigindo os requisitos necessários para que o sujeito possa se desenvolver com maestria, de acordo com suas possibilidades e/ou peculiaridades e que o contexto educativo possa ser espaço de transformação de vidas.

Makarenko tece críticas às concepções idealistas de uma definição ideal de "homem", bem como às teses funcionalistas, que procuram criar "moldes" para as personalidades de acordo com as necessidades da sociedade; segundo o educador, a "criança" não deve 
ser considerada como ser genérico, enfatiza que a coletividade deve ser tomada como objeto da educação, desta forma, todas as diferentes personalidades estariam contempladas (FILONOV, 2010, p. 31).

Os atos educativos precisam ser estabelecidos com confiança, sentimento que é desenvolvido no que-fazer educacional, diante de todas as relações comuns aos sujeitos envolvidos no cotidiano educacional, para que haja, realmente, probabilidades reais de um desenvolvimento pleno e/ou integral, para que os estudantes possam atuar em seus meios sociais com protagonismo diante de todas as adversidades da vivência.

O sujeito deve aprender a participar do seu ambiente de convivência com humanidade, mas também com autonomia, sem se submeter a situações opressoras do mundo capitalista, dialogando com intrepidez, visando sempre uma participação concisa nos espaços de relações profissionais que estejam interligadas ao desenvolvimento da pessoa humana em todo o tempo, acreditando que, como humanos, há sempre possibilidades de aprender, de crescer, de entender melhor o semelhante, enfim, de conviver com harmonia entre os pares, contribuindo para a constituição de um outro modo de organização da vida social.

Segundo o autor "é preciso mostrar aos alunos que o trabalho e a vida deles são uma parte do trabalho e da vida do país" (MAKARENKO, 1985, p. 97), demonstrando a inserção na realidade de forma concreta.

O autor destinou um lugar particular ao trabalho, ligado ao estudo das bases das ciências e a uma ampla educação cívica, política e moral. A educação pelo trabalho se daria integrada ao conjunto da organização do processo educativo, crianças e adolescentes deveriam participar das formas de trabalho úteis, adaptadas às suas idades e, nesta relação, tirariam partido da riqueza das relações que determinam o desenvolvimento da personalidade (FILONOV, 2010, p. 20).

Importante contextualizarmos o momento histórico em que Makarenko tecia suas considerações. Conforme Félix, Lenine, após a revolução de 1917, tinha um projeto ousado no que se refere a educação: "transformar a Rússia de dimensões continentais e com alto índice de analfabetismo em um país de homens e mulheres instruídos intelectualmente e com consciência política latente." A educação deveria aliar teoria e prática e pôr fim à dicotomia perpetuada por séculos (2005, p. 71).

Barato (2008), quando discorre sobre a categoria trabalho, enfatiza-o não apenas como meio de subsistência, "ganha-pão", mas também realização que dá sentido à vida do trabalhador. $\mathrm{O}$ autor pontua que a separação entre concepção e execução, na divisão do trabalho, priva o trabalhador de poder. Barato ainda reforça o papel da educação e o desafio de descobrir, no interior do próprio trabalho, bases capazes de fundar uma metodologia de formação profissional.

Para construir, ou re-construir, uma pedagogia baseada em saberes do trabalho, penso que é necessário examinar duas questões importantes. A primeira é a matriz interpretativa do conhecimento, que insiste na dicotomia teoria-prática. A segunda 
é a do sentido que a obra tem na organização da atividade, na constituição de atos de intenção, nos modos pelos quais o trabalhador valora o que faz, na estruturação do saber que resulta em produção, na formação de identidade e re-produção da força de trabalho (BARATO 2008 p. 7).

Saviani reforça esta dualidade quando faz uma retomada histórica do sentido e funções da educação, nos mostra o quanto a separação entre trabalho e educação é fruto da apropriação privada da terra e da divisão da nossa sociedade em classes. Segundo o autor, a educação desde então sofre uma cisão, onde uma é direcionada para a classe proprietária, centrada nas atividades intelectuais, e a outra é direcionada para a classe não proprietária, identificada como a educação dos serviçais, assimilada ao próprio processo de trabalho (SAVIANI 2007, p. 155).

Ciavatta (2009) também destaca o trabalho como princípio educativo, como uma característica inerente do trabalho; dessa maneira, entende-se que é possível ensinar o sujeito numa perspectiva de prepará-lo para compreender o trabalho como uma atividade humana, imprescindível para que o homem e a mulher produzam suas culturas, façam suas histórias, sejam protagonistas dos seus caminhos nos âmbitos pessoais e profissionais.

É possível relacionar esta leitura da Ciavatta (2009) com a pedagogia de Anton Makarenko sob a perspectiva de que, para os dois autores, o indivíduo deve ser preparado no âmbito educativo de maneira integral, tendo o trabalho sempre como possibilidade de intervir em seus mundos de vivência. $O$ trabalho está para além de uma compreensão de empregabilidade, perpassando por uma discussão e/ou compreensão de produção cultural e econômica, em que o sujeito sinta-se autor de suas produções, entendendo e realizando seus afazeres a favor de objetivos claros e concisos, que contribuam para o desenvolvimento da sociedade.

Pensar na formação do sujeito na EPT é entendê-lo com um sujeito social e coletivo, que deve ser instigado a conhecer as suas possibilidades de desenvolvimento, como também compreender o seu meio social e político com criticidade (CIAVATTA 2009). O processo educacional deve primar por uma preparação científica e humanística. Nesta perspectiva, é notório que as inferências corroboram com os ideários de Makarenko, pois reforçam que os estudantes devem, sim, ser estimulados a se desenvolver de maneira ímpar academicamente, porém, precisam ser, concomitantemente, instruídos a não se esquecer de sua condição humana.

“Como formação humana, o que se busca é garantir ao adolescente, ao jovem e ao adulto trabalhador o direito a uma formação completa, capaz de lhe oferecer condições para a leitura do mundo (...)" (CIAVATTA, 2009). Formação que, neste sentido, supõe a compreensão das relações sociais subjacentes a todos os fenômenos" (CIAVATTA, 2008). Uma formação humana que esteja centrada no desenvolvimento integral do sujeito estará contribuindo para a formulação de um cidadão crítico e participante de sua sociedade, que terá melhores e maiores condições de contribuir para o desenvolvimento de seu país. 
Filonov (2010), quando nos traz as contribuições de Makarenko, pontua a irresponsabilidade do ato de estabelecer um trabalho educativo que não tenha objetivos claros. O processo educativo, sob esta perspectiva, jamais pode ser concebido sem um aspecto intencional e político, portanto, é preciso ter objetivos políticos perante suas ações. Nada pode ser neutro mediante a práxis educacional, afinal, acredita-se no processo educacional que prepare cidadãos conscientes e críticos, os quais possam atuar em seus meios sociais com brilhantismo.

Para tanto, é necessário ter planejamento, conhecer as exigências da sociedade vigente, a fim de que o educando esteja preparado para trabalhar com eficácia em seus ambientes de subsistência, respondendo aos anseios de uma preparação profissional que seja crítica. Corrobora com este pensar a autora Rehem: "para viver e produzir nesses cenários é necessário dispor de mecanismos adequados para dar hospitalidade à crítica, agir com autonomia e criatividade, sem se deixar sucumbir pelas forças vorazes da fluidez capitalista" (REHEM, 2009, p. 43).

Alcançar esses objetivos requer conhecer a sociabilidade comum ao contexto de vida dos estudantes e no qual a escola está inserida; e perpassa avaliar quais são os verdadeiros conteúdos a serem desenvolvidos, numa específica época das suas vidas, a fim de que sejam realmente importantes para o desenvolvimento integral desses sujeitos.

Acerca do processo de seleção dos conteúdos a serem aplicados aos estudantes, na perspectiva de um processo educacional integrador e transformador de vidas, têm-se as palavras de Sacristán (2000), que sublinha: "o currículo molda os docentes, mas é traduzido na prática por eles mesmos, a influência é recíproca" (SACRISTÁN, 2000, p. 165). É notória a necessidade de uma postura crítica por parte do docente para que haja uma formação integral, efetivada frente os estudantes da EPT; para tanto, tal criticidade precisa permear toda atmosfera da ambiência educativa.

Sacristán (2000) ainda sublinha a seguinte questão: "quem, a não ser o professor, pode moldar o currículo em função das necessidades de determinados alunos, ressaltando os seus significados, de acordo com suas necessidades pessoais e sociais dentro de um contexto cultural?" (SACRISTÁN, 2000, p. 168). Acredita-se no papel revolucionário do docente, o qual pode conhecer os seus educandos, de maneira que eles sejam estimulados a se desenvolver da melhor maneira possível, perpassando as limitações comuns de seus espaços de vivência, conjecturando novas formas de ver e atuar no mundo, desvencilhando espaços outrora intransponíveis, onde os conhecimentos adquiridos propiciem, além de uma mudança perante o mundo, novas caminhadas de vida.

É importante primar pelos aspectos coletivos no desenvolvimento dos atos educativos no cotidiano da escola, capacitando as pessoas para trilharem seus caminhos com maestria, só assim poderão também contribuir para a concretização de ações que façam da sociedade um lugar mais harmonioso de viver, como bem enfatiza o Mestre 
Paulo Freire: " transformando o mundo injusto e ofensivo em mundo menos odiento, em mundo mais genteficado" (2012, p. 53).

Entende-se que quanto mais os sujeitos tomam consciência de si e do mundo que os cerca, maiores serão as possibilidades de mudança de cultura, ou seja, é relevante dialogar, mostrar o mundo sob a ótica da criticidade para os estudantes, a fim de que estes tenham condições autônomas de escolher os seus caminhos e possam influenciar positivamente nas condições de vida dos seus semelhantes, contribuindo para o desenvolvimento dos seus ambientes de convivência humana.

Contudo, faz-se relevante a vigente reflexão sob a ótica de Makarenko:

a única tarefa organizativa digna da nossa época pode ser a criação de um método que, sendo comum e único, permita simultaneamente que cada personalidade independente desenvolva suas aptidões, mantenha a sua individualidade e avance pelo caminho das suas vocações (FILONOV, 2010, p. 49).

O trabalho docente, ao convergir esforços para estimular o educando a trilhar o seu caminho acadêmico com toda autonomia possível, contribui com uma atuação no mundo através de uma educação transformadora e emancipatória e essa ação perpassa atos educativos que valorizem a pessoa humana em sua singularidade, exigindo uma atitude de atendimento peculiar frente às especificidades de cada indivíduo em sala de aula.

\section{Considerações}

Pensar na coletividade educativa sob a luz das leituras de Makarenko é proporcionar momentos de desenvolvimento aos indivíduos, fazendo com que entendam o mundo à medida em que vão se conhecendo como sujeitos desse "mundo" e aprendendo a se relacionar consigo mesmos e com os seus semelhantes. Sendo assim: "Numa coletividade bem organizada, todo o processo educativo é realizado sem esforços especiais, como uma assimilação incessante de impressões, comportamentos e relações mais sutis e diversificadas" (FILONOV, 2010, p. 53).

Filonov (2010) inspirado nas leituras de Makarenko sublinha que:

educar um ser humano significa formar nele capacidades para que possa escolher vias com perspectivas. A metodologia deste trabalho consiste em organizar novas perspectivas, em utilizar as existentes, em colocar, pouco a pouco, outras mais elevadas (FILONOV, 2010, p. 76, 77).

Evidencia-se neste contexto a relevância de ensinar com alegria, motivando sempre os estudantes a trilharem os seus caminhos acadêmicos com entusiasmo: "a vida da coletividade deve ser cheia de alegria neste sentido, não uma alegria de simples divertimento 
e satisfação no dado momento, imediata, mas uma alegria provocada pelas tensões e êxito de trabalho do dia de amanhã" (FILONOV, 2010, p. 81).

Ensinar com alegria não é ter o deslumbramento de dias totalmente felizes ou a visão inocente de acreditar que tudo "são flores", porém, é encantar-se constantemente, crendo que os atos educativos realizados com responsabilidade e comprometimento, frente ao processo de constituir conhecimentos, pode ser possível. Tendo essa esperança e trabalhando em prol do respeito pleno ao desenvolvimento do humano, tendo, assim, a certeza da alegria em disseminar conhecimentos, tendo e promovendo a premissa do respeito aos seus iguais em todo o tempo na ambiência educativa e a partir das singularidades de cada um, é enaltecer a boniteza de se viver respeitosamente em favor da coletividade.

A condução da docência nos dias atuais requer uma postura de respeito mútuo ao ser humano, sujeito do processo de ensino e aprendizagem e, para que este respeito seja propagado entre todos os indivíduos no contexto escolar, a fim de que haja condições propícias para a efetivação de uma coletividade harmoniosa, é necessário que a maneira de educar seja esperançosa, permeada de atitudes acolhedoras, ao mesmo tempo que direcione o estudante aos caminhos possíveis, um processo educativo que seja mediador de novas e úteis possibilidades, para que sua vida seja repleta de perspectivas para um crescimento concreto e feliz, e que, indubitavelmente, o indivíduo alcance seus objetivos críticos e autônomos em suas ambiências políticas, sociais e históricas.

Ao buscarmos inspiração na obra do educador Makarenko, pretendemos retomar um pouco a esperança de que este e outros autores nos auxiliem na resistência necessária que a realidade atual nos exige.

Recebido em: 29/10/2019 e Aprovado em: 15/11/2019

\section{Referências}

ARANHA, Maria Lúcia de Arruda. História da educação e da pedagogia: geral e Brasil. 3 ed. São Paulo: Moderna, 2006.

BARATO, Jarbas Novelino Barato. Conhecimento, trabalho e obra: uma proposta metodológica para a educação profissional. B.Téc.Senac, Rio de Janeiro, v. 34, n. 3, set/dez. 2008.

CIAVATTA, Maria. Mediações históricas de trabalho e educação: gênese e disputas na formação dos trabalhadores. Rio de Janeiro: Lamparina, CNPq, Faperj, 2009.

Maria. A formação integrada: a escola e o trabalho como lugares de memória e de identidade. Periódico: Trabalho Necessário, 2008. Disponível em: http://periodicos.uff.br/trabalhonecessario/article/ view/6122/5087 Vários acessos 
FELIX, Leiliane Aparecida Alcantara. Antón Makarenko e a construção de uma teoria pedagógica a partir da práxis educativa: a educação do homem socialista. Dissertação (Mestrado em Educação) - Universidade Estadual de Maringá. Orientador: João Luiz Gasparin. Maringá, 2015. Disponivel em: https://sucupira.capes.gov.br/sucupira/public/consultas/coleta/trabalhoConclusao/ viewTrabalhoConclusao.jsf?popup=true\&id_trabalho=2847230\#. Acesso em março de 2019.

FILONOV, G. N. Anton Makarenko. Recife: Fundação Joaquim Nabuco, Editora Massangana, 2010.

FREIRE, Paulo. À sombra desta mangueira. 10ạ ed. Rio de Janeiro: Civilização Brasileira, 2012.

MAKARENKO, A. S. Poema pedagógico. Tradução de Tatiana Belinky. São Paulo: Brasiliense, 1985.

MAKARENKO, Anton. Obras, v. 1-7. Moscou: Editorial Progresso, 1957.

REHEM, Cleunice Matos. Perfil e formação do professor de educação profissional técnica. São Paulo: Editora Senac, 2009.

SACRISTÁN, José Gimeno. O currículo: uma reflexão sobre a prática. 3 ed. Porto Alegre: Art. Med, 2000.

SAVIANI, Demerval. Trabalho e educação: fundamentos ontológicos e históricos. Revista Brasileira de Educação, v. 12, n. 34, jan/abril 2007. 